\title{
The association between dietary protein intake and colorectal cancer risk: a meta- analysis
}

\author{
Renxu Lai", Zhuang Bian, Hong Lin, Jiangnan Ren, Huaili Zhou and Huixue Guo
}

\begin{abstract}
Background: Association between dietary protein intake and colorectal cancer risk has not been fully quantified, while the results were controversial. This study aimed to evaluate the role of protein intake in the development of colorectal cancer.

Methods: PUBMED and EMBASE were searched up to December 2016. Two independent reviewers independently extracted data from eligible studies. Relative risk (RR) with 95\% confidence intervals (Cl) was pooled using randomeffects model to estimate the result. Besides, publication bias and sensitivity analysis were conducted.

Results: Thirteen articles involving 21 studies comprising 8187 cases were included in this report. The pooled RR of colorectal cancer was $1.006(95 \% \mathrm{Cl}=0.857-1.179)$ indicating that there is no significant association between dietary protein intake and colorectal cancer risk. Furthermore, the pooled RRs for colon cancer and rectum cancer were $1.135(95 \% \mathrm{Cl}=0.871-1.480)$ and $0.773(95 \% \mathrm{Cl}=0.538-1.111)$, respectively, with the highest category of dietary protein intake. The association was not significant either in subgroup analysis of study design, protein type (animal protein or vegetable protein), sex, and or geographic locations.

Conclusions: The present study indicated that the highest category compared to the lowest category of protein intake had no significant association on colorectal cancer risk. Dose-response analysis was not conducted due to limited information provided. Therefore, more studies with large cases and participants as well as detailed amounts of dietary protein intake are wanted to confirm this result.
\end{abstract}

Keywords: Protein intake, Colorectal cancer, Meta-analysis, Relative risk

\section{Background}

Colorectal cancer is one of the high incidence of malignant tumors worldwide, with the morbidity and mortality ranking third among malignant tumors in the Western world [1]. Owing to economic development, air and water pollution, and changing lifestyle to high-protein, highcarbohydrate, and high-fat diet, the incidence and mortality of colorectal cancer has been on a rising trend in China [2]. In general, physical activity, low total energy intake such as dietary protein, low red and processed meat consumption, and limited alcohol drinking were known to give beneficial effect for cancer prevention [3]. Diet has long been regarded as the most important lifestyle risk

\footnotetext{
* Correspondence: lairenxu@126.com

Department of Gastroenterology, The Fifth Affiliated Hospital of Sun Yat-sen University, No.52, Meihua East Road, Zhuhai, Guangdong 519000, China
}

factor for colorectal cancer. However, role of many dietary factors in colon carcinogenesis remains unresolved.

In animal and in vitro studies which investigated the effect of protein intake on colorectal cancer risk, highprotein diet could lead to DNA damage of colonocytes, decrease colonic mucosal thickness, and reduce the height of the colonocyte brushborder membrane [4-6]. Several epidemiologic studies have explored the relationship between dietary protein intake and the risk of colorectal cancer, but the results are inconsistent. A recent study by Tayyem RF et al. reported that the highest intake of protein could increase colorectal cancer risk [7]. However, Sun Z et al. found that colorectal cancer risk could be reduced with the highest category intake of protein [8]. Furthermore, Yang SY et al. failed to find any significant association between them [9]. So far, 
there is no meta-analysis conclusively demonstrating the relationship between them. In this study, a comprehensive meta-analysis of observational studies was performed to assess the colorectal cancer risk associated with dietary protein intake. The aim of this report was also to assess the heterogeneity and publication bias.

\section{Methods}

\section{Search strategy}

This meta-analysis followed the "Preferred Reporting Items for Systematic Reviews and Meta-Analyses" (PRISMA) guidelines [10]. We systematically searched PubMed and Embase (from their commencements to December 2016) for studies with the following format: (protein OR nutrition) AND (colorectal cancer OR colon cancer OR rectum cancer). In addition, the reference lists of relevant articles were also reviewed to find other suitable articles.

\section{Study selection}

Studies were included if they met all of the following criteria: (1) the study subjects were adults ( $\geq 18$ years old) without specific diseases at study baseline; (2) the study was conducted with observational studies; (3) the exposure of interest was dietary intake of protein with two or more quantitative categories; (4) the outcome of interest was colorectal cancer, colon cancer, or rectum cancer; and (5) relative risk (RR) and 95\% confidence intervals (CI) for dietary protein intake (or there are sufficient data to compute them was also acceptable).

\section{Data exaction and quality assessment}

The following data from each study were extracted independently by two authors: the first author's name, publication year, study location, age and sex of the study population, outcomes of disease type, type of protein intake, number of cases and controls, variables adjusted in each original study, and RR with their 95\% CI. If the paper reported total protein, animal protein, and vegetable protein at the same time, we used the data of the total protein for the whole analysis and animal protein or vegetable protein for the subgroup analysis if possible. Otherwise, animal protein and vegetable protein was as an independent study for the whole analysis. Furthermore, sex (male or female) and disease type (colorectal cancer, colon cancer, or rectum cancer) was analyzed as the same as protein type. Newcastle-Ottawa Scale (NOS) was used to assess the quality of included studies [11], which can either be used as a checklist or scale. The full score was nine stars, and a study with $\geq 6$ stars was defined with high-quality.

\section{Statistical analysis}

The pooled RR with 95\% CI was calculated using randomeffects models with the method of DerSimonian and Laird, which considers both within-study and betweenstudy variation [12]. The between-study heterogeneity in the association between dietary protein intake and colorectal cancer was assessed using chi-square test and $I^{2}$ test, and $<25 \%, 25-50 \%$, and $>75 \%$ represents low, moderate, and severe heterogeneity, respectively $[13,14]$. Subgroup analyses were performed by disease type, study design, sex, protein type, and geographic locations. Sensitivity analysis was performed to assess whether the results could be affected while removing a single study [15]. The individual study is thought to produce excessive influence, if the point estimate lies outside the $95 \% \mathrm{CI}$ of the combined analyses. Small study effect was assessed with visual inspection of the Egger's test and funnel plot [16]. We used STATA version 12.0 (Stata Corporation, College Station, TX, USA) for the meta-analysis. Two-tailed $P \leq 0.05$ was accepted as statistically significant for computed effects.

\section{Results}

\section{Characteristics of studies and data quality}

We have searched databases of PubMed and Embase and finally got 3069 articles. We then reviewed the titles and abstracts to exclude 3034 articles because of duplicates $(n=986)$, obvious irrelevance $(n=2022)$, and animal or cell studies $(n=26)$. Twenty-two of the remaining 35 articles are excluded due to the following reasons: review articles $(n=6)$, duplicate publications $(n=1)$, letter to the editors $(n=2)$, and paper provided insufficient data $(n=13)$. Finally, 13 articles [7-9, 17-26] were included in this study. Two articles [22, 25] reported colon cancer and rectum cancer, two articles [23, 24]

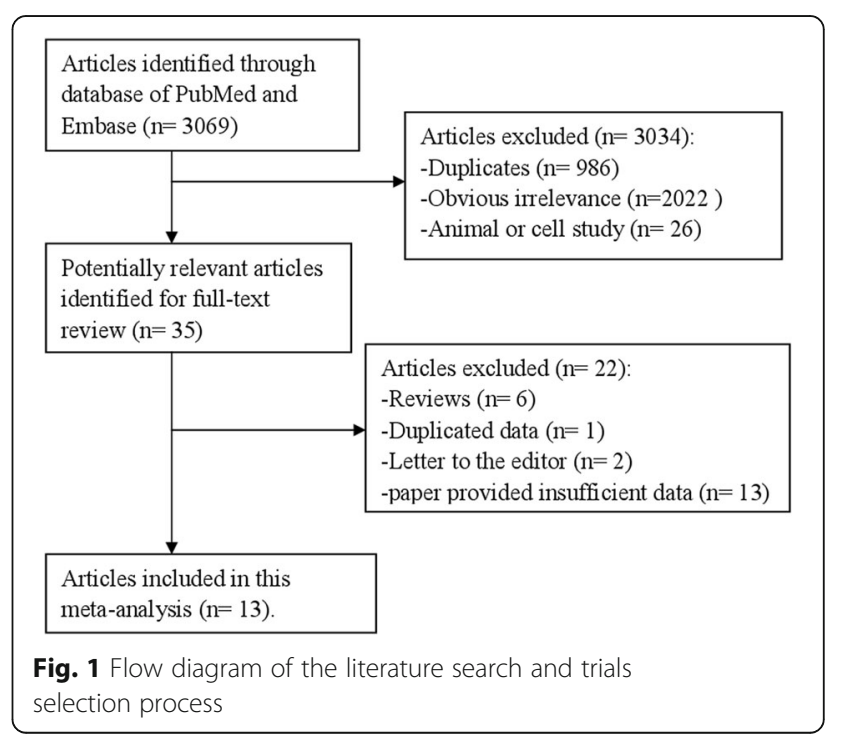




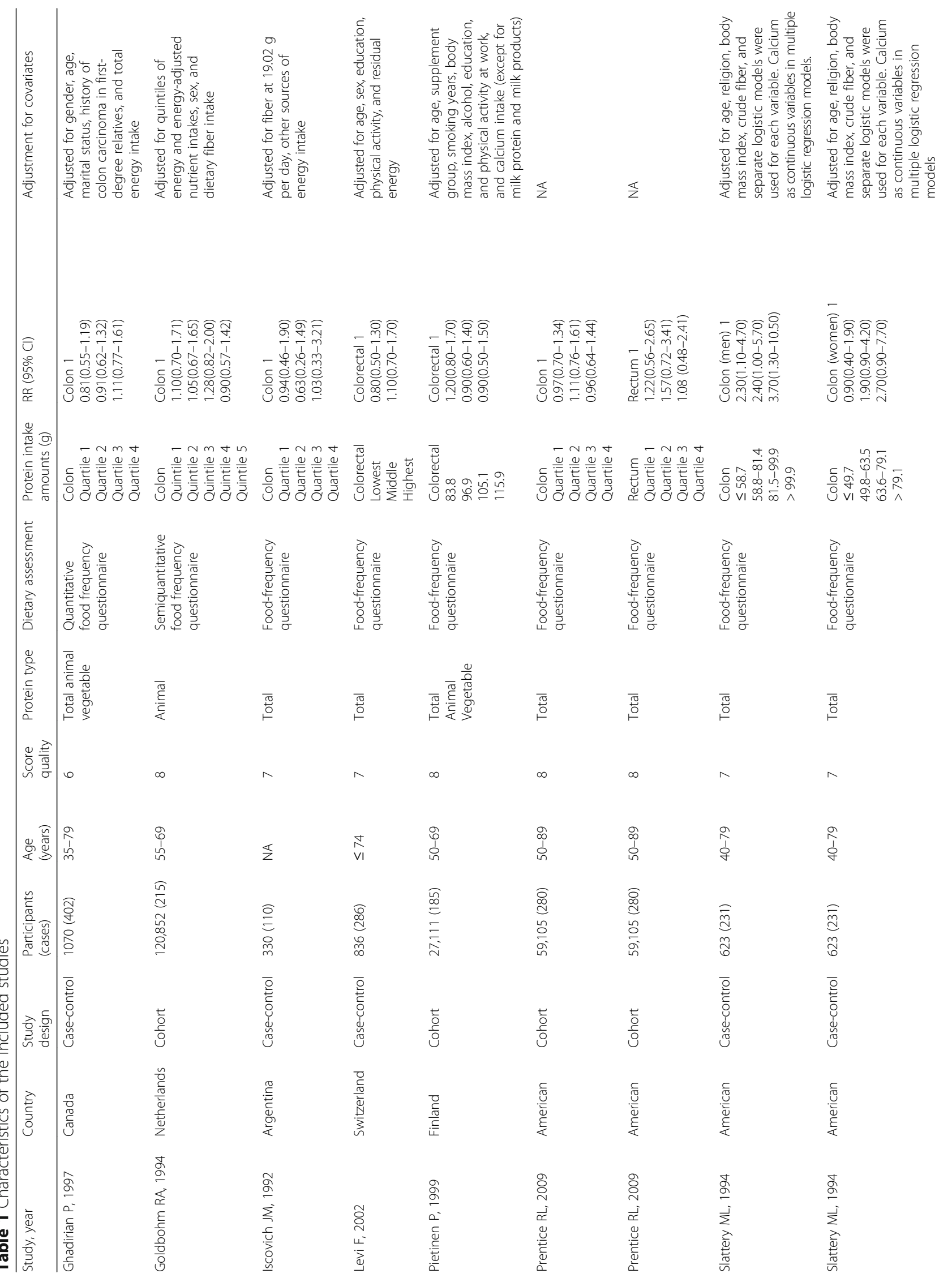




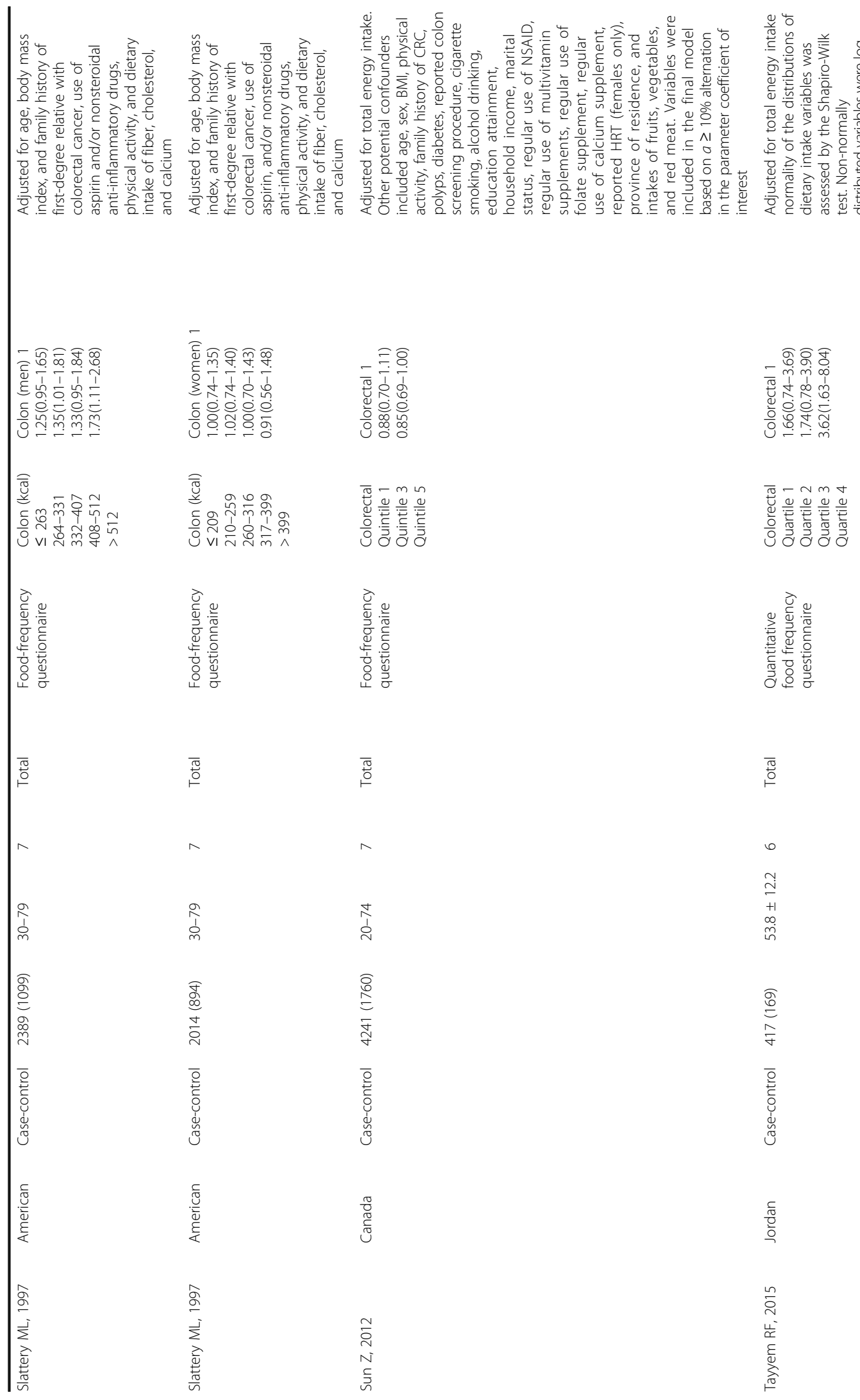




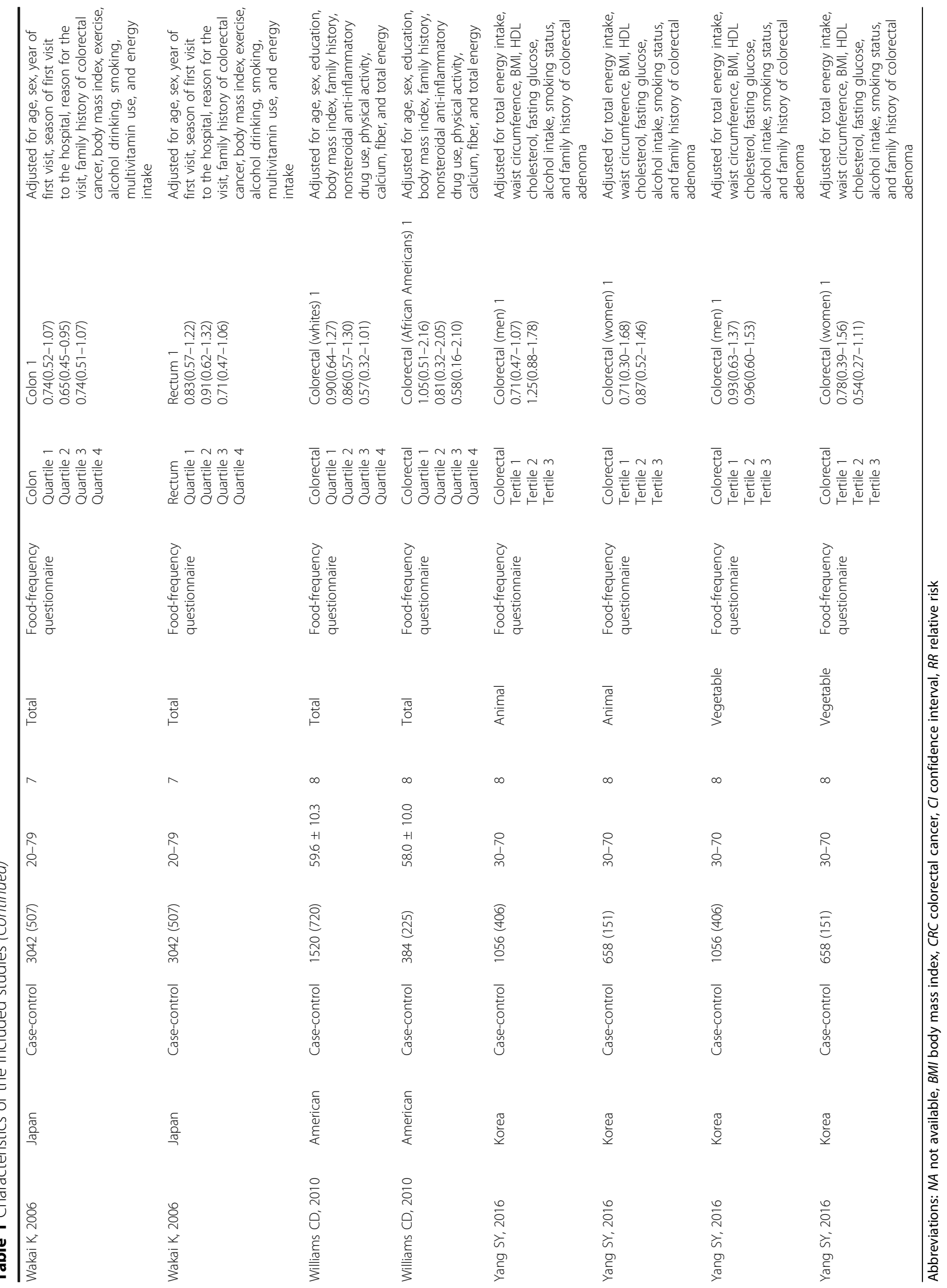


reported male populations and female populations, one article [26] reported Whites and African Americans, and one article [9] reported animal protein and vegetable protein, respectively. Therefore, 21 studies involving 8187 cases were used for the analysis. And the screening process was showed by Fig. 1 . The average NOS score was 7.23 , and all included studies were with high quality (over six stars). The details of the quality score for every study are shown in Additional file 1: Table S1. The characteristics of included studies are listed in Table 1.

\section{Dietary protein intake and risk of colorectal cancer}

To assess if the intake of protein could influence the colorectal cancer risk, we used random-effect model to pool the study-specific RR. Compared with the lowest category of protein intake, the pooled RR of colorectal cancer for the highest category was 1.006 (95\% CI $=0.857-1.179)$ indicating that highest category of dietary protein intake had no significant association on colorectal cancer risk (Fig. 2). Heterogeneity was found to be significant $\left(I^{2}=53.4 \%, p=0.002\right)$.

\section{Sources of heterogeneity and subgroup analysis}

In the pooled results of the overall studies, significant heterogeneity was demonstrated for the associations between dietary protein intake and colorectal cancer risk. Thus, we used univariate meta-regression to explore the reason of causing with the covariates of publication year, disease type, study design, protein type (animal protein or vegetable protein), sex, and geographic locations. No significant findings were found contributing significantly to the between-study heterogeneity.

Subgroup analyses were also conducted to explore the potential relationship and heterogeneity. For the subgroup of disease type, the pooled RRs for colon cancer and rectum cancer were $1.135(95 \% \mathrm{CI}=0.871-1.480)$ (Fig. 3) and $0.773(95 \% \mathrm{CI}=0.538-1.111)$ with the highest category of dietary protein intake, respectively. As different types of proteins could influence the risk of colorectal cancer, a subgroup analysis has been conducted. The results showed that no evidence of significance was found between dietary animal protein or vegetable protein intake and colorectal cancer risk. When we conducted the subgroup analysis by study

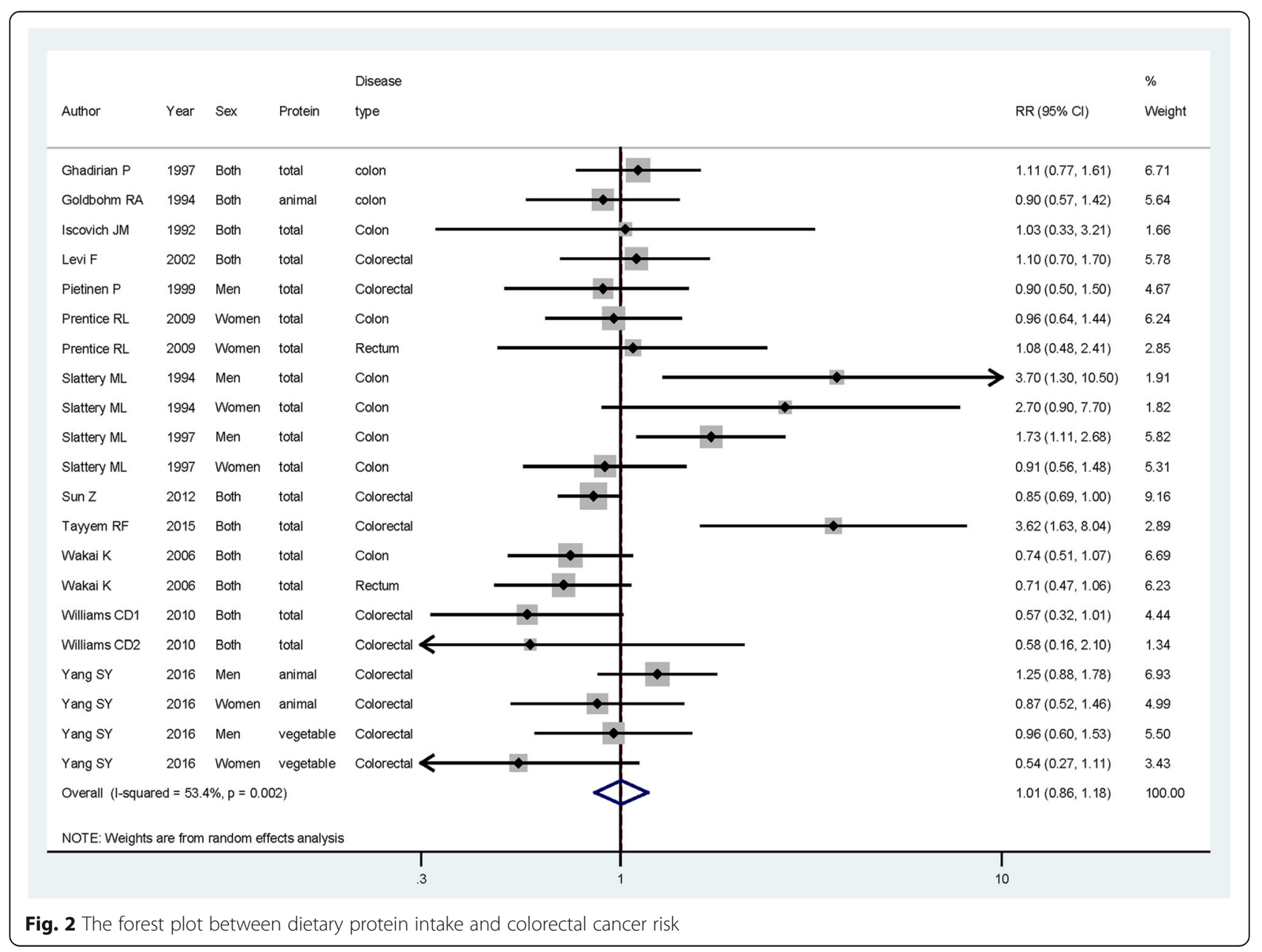




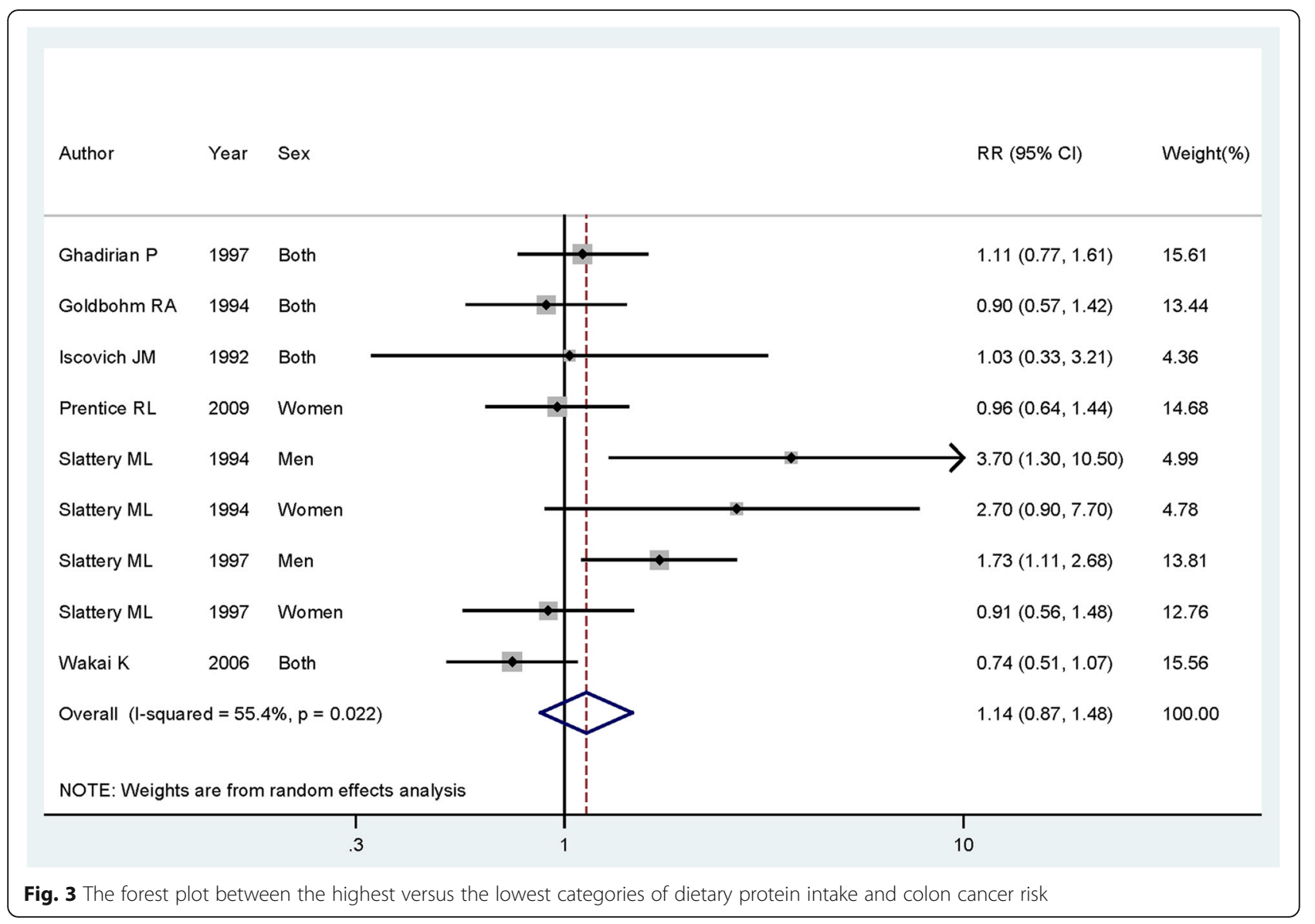

design, the highest dietary protein intake levels had nonsignificant association for colorectal cancer risk either in cohort studies or in case-control studies. In a stratified analysis by sex and geographic locations, the association was consistent with the overall result. The detailed results are shown in Table 2.

\section{Sensitive analysis}

In a sensitivity analysis excluding a single study at a time, no individual study would affect the whole result.

\section{Publication bias}

The Egger's test $(P=0.201)$ and Begg's funnel plot (Fig. 4) detected no obvious publication bias.

\section{Discussion}

Findings from this report of observational studies indicated that no evidence of significant association was found on colorectal cancer risk with the highest category of dietary protein intake. The association was not significant either in the colon cancer risk or in the rectum cancer risk with the highest category of dietary protein intake. The results of subgroup analyses by study design, protein type, sex, and geographic locations were consistent with the overall pooled result. To our knowledge, this is the first comprehensive report conducted to assess the relation between dietary protein intake and colorectal cancer risk. Although we did not find any positive result between them, a large number of colorectal cancer cases could allow a much greater possibility of reaching reasonable conclusions.

Significant between-study heterogeneity was found in the process of merging results $\left(I^{2}=53.4 \%, P_{\text {heterogeneity }}=0.002\right)$. However, heterogeneity is common in the meta-analysis [27]. Meta-regression was used to explore the potential covariates that cause between-study heterogeneity. All the covariates of publication year, disease type, study design, protein type, sex, and geographic locations were not found any significant contributed to the heterogeneity. Furthermore, subgroup analyses by disease type, study design, protein type, sex, and geographic locations were performed to explore the high heterogeneity. To our attention, the heterogeneity was not significant either in the animal protein studies $\left(I^{2}=0.0 \%, P_{\text {heterogeneity }}=0.624\right)$ or vegetable protein studies $\left(I^{2}=49.9 \%, P_{\text {heterogeneity }}=0.112\right)$. Therefore, the protein type may increase the heterogeneity to the whole results. 
Table 2 Combined overall and subgroup results

\begin{tabular}{|c|c|c|c|c|c|}
\hline Subgroups & No. cases & No. studies & RR $(95 \% \mathrm{Cl})$ & $P^{2}(\%)$ & $P_{\text {heterogeneity }}$ \\
\hline All studies & 8187 & 21 & $1.006(0.857-1.179)$ & 53.4 & 0.002 \\
\hline \multicolumn{6}{|l|}{ Disease type } \\
\hline Colon & 3446 & 9 & $1.135(0.871-1.480)$ & 55.4 & 0.022 \\
\hline Rectum & 282 & 2 & $0.773(0.538-1.111)$ & 0.0 & 0.363 \\
\hline \multicolumn{6}{|l|}{ Study design } \\
\hline Cohort & 680 & 4 & $0.939(0.730-1.209)$ & 0.0 & 0.980 \\
\hline Case-control & 7507 & 17 & $1.030(0.846-1.254)$ & 62.6 & 0.000 \\
\hline \multicolumn{6}{|l|}{ Sex } \\
\hline Both & 4394 & 10 & $0.913(0.737-1.132)$ & 53.3 & 0.023 \\
\hline Men & 2204 & 5 & $1.306(0.932-1.829)$ & 54.6 & 0.066 \\
\hline Women & 1589 & 6 & $0.931(0.710-1.220)$ & 20.5 & 0.279 \\
\hline \multicolumn{6}{|l|}{ Protein } \\
\hline Total & 6858 & 16 & $1.049(0.856-1.285)$ & 60.6 & 0.001 \\
\hline Animal & 1359 & 5 & $1.041(0.866-1.252)$ & 0.0 & 0.624 \\
\hline Vegetable & 1144 & 4 & $0.851(0.602-1.203)$ & 49.9 & 0.112 \\
\hline \multicolumn{6}{|c|}{ Geographic locations } \\
\hline America & 5711 & 11 & $1.072(0.838-1.372)$ & 56.4 & 0.011 \\
\hline Asia & 1790 & 7 & $0.962(0.694-1.333)$ & 69.0 & 0.004 \\
\hline Europe & 686 & 3 & $0.972(0.738-1.280)$ & 0.0 & 0.785 \\
\hline
\end{tabular}

To our attention, various studies showed an opposite correlation (some positive and others inverse) between dietary intake of protein and colorectal cancer. The methods of dietary assessment in all the included studies are food frequency questionnaire (FFQ). Subgroup analysis by geographic locations was conducted to find the

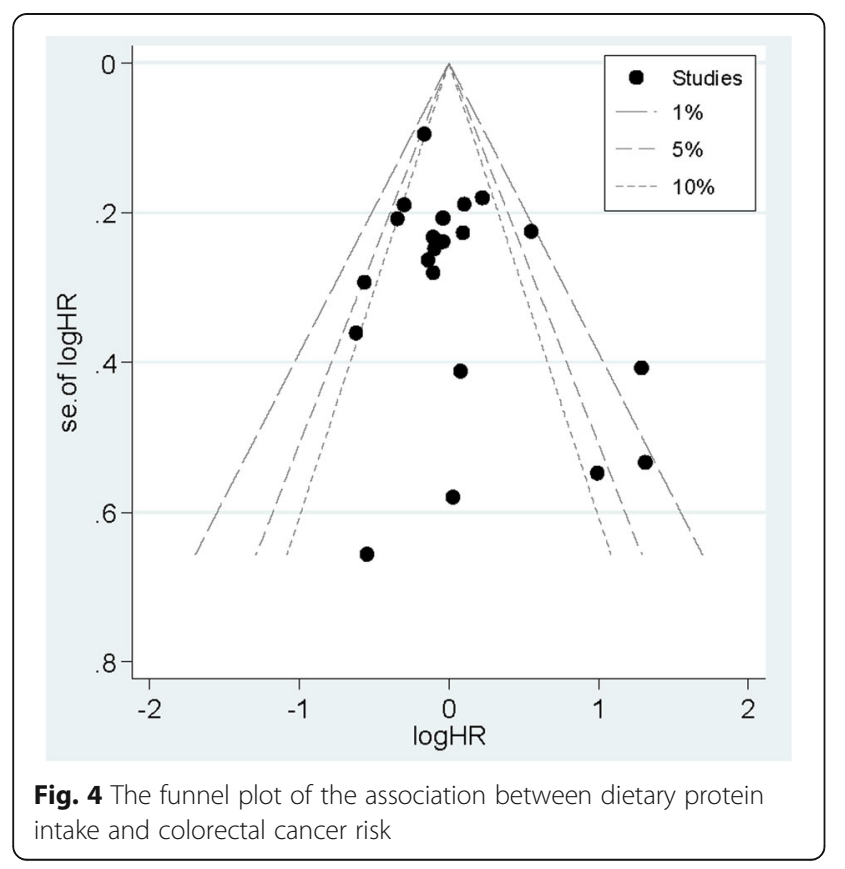

opposite correlation between dietary intake of protein and colorectal cancer, but there is no significant association among American populations, Asian populations, or European populations. The detailed amounts of dietary protein intake are not provided in most studies. Then, we did not consider the influences of dietary intake considerations to the colorectal cancer risk. Furthermore, the results are unstable due to the small sample size in each independent study. Therefore, this meta-analysis was performed to obtain a comprehensive result of this issue.

Several restrictions in this report should be attended. Firstly, our study included 21 individual studies; therefore, many diversification such as adjustments and quality that may influence the whole result. Secondly, although most of the included studies have adjusted for potential confounding factors, such as age, sex, and BMI, we cannot rule out the possibility that some other un-measured factors, such as intake of other energy, might have been partly responsible for the observed association. Thirdly, due to the limited information in the reported studies, dose-response analysis was not performed for dietary protein intake and colorectal cancer risk. Therefore, detailed information for each category of protein intake is wanted to assess the relationship between protein intake and colorectal cancer. Fourthly, dietary protein intake was collected via food-frequency questionnaires (FFQs), recall bias, and measurement bias 
could not be eliminated. Finally, significant heterogeneity was observed across studies included in the present meta-analysis. And the between-study heterogeneity was not resolved by meta-regression, the results of subgroup analyses were also with high heterogeneity in some groups except in the subgroup of protein type. Therefore, dietary protein type (animal protein or vegetable protein) may be the potential contributor to the between-study heterogeneity, and it would be further affecting the heterogeneity.

\section{Conclusions}

In summary, this study suggested that the highest category of dietary protein intake had no significant association for the risk of colorectal cancer. Therefore, further studies with large cases and participants as well as detailed amounts of dietary protein intake are wanted to confirm this result, during some limitation that existed in our study.

\section{Additional file}

Additional file 1: Table S1. The details of quality score for the included study. (DOCX $12 \mathrm{~kb}$ )

\section{Abbreviations}

Cl: Confidence intervals; HR: Hazard ratio; NOS: Newcastle-Ottawa Scale; OR: Odds ratio; PRISMA: Preferred Reporting Items for Systematic Reviews and Meta-Analyses; RR: Risk ratio

\section{Acknowledgements}

None.

\section{Funding}

None.

\section{Availability of data and materials}

Data sharing not applicable to this article as no datasets were generated or analyzed during the current study.

\section{Authors' contributions}

$R X L$ and $Z B$ conceived of the study. $R X L, Z B$, and $H L$ carried out the literature searching. $R X L, Z B$, and $H L$ are responsible for the data extraction. JNR and $H L Z$ analyzed the data. RXL drafted the manuscript. $R X L, Z B, H L, J N R, H L Z$, and $\mathrm{HXG}$ did the final approval of the version to be submitted.

\section{Ethics approval and consent to participate}

Not applicable.

\section{Consent for publication}

Not applicable.

\section{Competing interests}

The authors declare that they have no competing interests.

\section{Publisher's Note}

Springer Nature remains neutral with regard to jurisdictional claims in published maps and institutional affiliations.
Received: 9 March 2017 Accepted: 25 August 2017

Published online: 08 September 2017

\section{References}

1. Siegel R, Desantis C, Jemal A. Colorectal cancer statistics, 2014. CA Cancer J Clin. 2014;64(2):104-17.

2. Zheng ZX, Zheng RS, Zhang SW, et al. Colorectal cancer incidence and mortality in China, 2010. Asian Pac J Cancer Prev. 2014;15(19):8455-60.

3. Wiseman M. The second World Cancer Research Fund/American Institute for Cancer Research expert report. Food, nutrition, physical activity, and the prevention of cancer: a global perspective. Proc Nutr Soc. 2008;67(3):253-6.

4. Toden S, Bird AR, Topping DL, et al. Resistant starch prevents colonic DNA damage induced by high dietary cooked red meat or casein in rats. Cancer Biol Ther. 2006;5(3):267-72.

5. Toden S, Bird AR, Topping DL, et al. Resistant starch attenuates colonic DNA damage induced by higher dietary protein in rats. Nutr Cancer. 2005;51(1):45-51.

6. Andriamihaja M, Davila AM, Eklou-Lawson M, et al. Colon luminal content and epithelial cell morphology are markedly modified in rats fed with a highprotein diet. Am J Physiol Gastrointest Liver Physiol. 2010;299(5):G1030-7.

7. Tayyem RF, Bawadi HA, Shehadah IN, et al. Macro- and micronutrients consumption and the risk for colorectal cancer among Jordanians. Nutrients. 2015;7(3):1769-86.

8. Sun Z, Liu L, Wang PP, et al. Association of total energy intake and macronutrient consumption with colorectal cancer risk: results from a large population-based case-control study in Newfoundland and Labrador and Ontario, Canada. Nutr J. 2012;11:18.

9. Yang SY, Kim YS, Lee JE, et al. Dietary protein and fat intake in relation to risk of colorectal adenoma in Korean. Medicine (Baltimore). 2016;95(49):e5453.

10. Moher D, Liberati A, Tetzlaff J, et al. Preferred reporting items for systematic reviews and meta-analyses: the PRISMA statement. Ann Intern Med. 2009; 151(4):264-9. W64

11. Stang A. Critical evaluation of the Newcastle-Ottawa scale for the assessment of the quality of nonrandomized studies in meta-analyses. Eur J Epidemiol. 2010;25(9):603-5.

12. DerSimonian R, Laird N. Meta-analysis in clinical trials. Control Clin Trials. 1986;7(3):177-88.

13. Higgins JP, Thompson SG, Deeks JJ, et al. Measuring inconsistency in metaanalyses. BMJ. 2003;327(7414):557-60.

14. Higgins JP, Thompson SG. Controlling the risk of spurious findings from meta-regression. Stat Med. 2004;23(11):1663-82.

15. Tobias A. Assessing the influence of a single study in the meta-analysis estimate. Stata Tech Bull. 1999;47:15-8.

16. Egger M, Davey Smith G, Schneider M, et al. Bias in meta-analysis detected by a simple, graphical test. BMJ. 1997;315(7109):629-34.

17. Ghadirian P, Lacroix A, Maisonneuve $\mathrm{P}$, et al. Nutritional factors and colon carcinoma: a case-control study involving French Canadians in Montreal, Quebec, Canada. Cancer. 1997:80(5):858-64.

18. Goldbohm RA, van den Brandt PA, Van't veer $\mathrm{P}$, et al. A prospective cohort study on the relation between meat consumption and the risk of colon cancer. Cancer Res. 1994;54(3):718-23.

19. Iscovich JM, L'Abbe KA, Castelleto $R$, et al. Colon cancer in Argentina. II: risk from fibre, fat and nutrients. Int J Cancer. 1992;51(6):858-61.

20. Levi F, Pasche C, Lucchini F, et al. Macronutrients and colorectal cancer: a Swiss case-control study. Ann Oncol. 2002;13(3):369-73.

21. Pietinen $P$, Malila N, Virtanen $M$, et al. Diet and risk of colorectal cancer in a cohort of Finnish men. Cancer Causes Control. 1999:10(5):387-96.

22. Prentice RL, Shaw PA, Bingham SA, et al. Biomarker-calibrated energy and protein consumption and increased cancer risk among postmenopausal women. Am J Epidemiol. 2009;169(8):977-89.

23. Slattery ML, Potter JD, Sorenson AW. Age and risk factors for colon cancer (United States and Australia): are there implications for understanding differences in case-control and cohort studies? Cancer Causes Control. 1994;5(6):557-63.

24. Slattery ML, Caan BJ, Potter JD, et al. Dietary energy sources and colon cancer risk. Am J Epidemiol. 1997;145(3):199-210.

25. Wakai K, Hirose K, Matsuo K, et al. Dietary risk factors for colon and rectal cancers: a comparative case-control study. J Epidemiol. 2006;16(3):125-35.

26. Williams CD, Satia JA, Adair LS, et al. Associations of red meat, fat, and protein intake with distal colorectal cancer risk. Nutr Cancer. 2010;62(6):701-9.

27. Munafò MR, Flint J. Meta-analysis of genetic association studies. Trends Genet. 2004;20(9):439-44. 